\title{
MARIA - INTERDITADA E ESTERILIZADA: REFLEXÕES JURÍDICAS ACERCA DO TRANSTORNO MENTAL
}

\author{
Luthianne Perin Ferreira Lunardi \\ Universidade Regional Integrada do Alto Uruguai e das \\ Missões, Campus Santo Ângelo (URI), Rio Grande do Sul. \\ luthianne@san.uri.br \\ Taciana Damo Cervi \\ Universidade Regional Integrada do Alto Uruguai e das \\ Missões, Campus Santo Ângelo (URI), Rio Grande do Sul. \\ taciana@san.uri.br \\ Alguém devia ter caluniado Josef K., porque foi preso uma manhã, sem que ele \\ houvesse feito alguma coisa de má. \\ Kafka, O Processo
}

RESUMO: O estudo investiga os interesses envolvidos no deferimento do pedido de interdição e de esterilização compulsória, por meio de laqueadura tubária, em Maria, pessoa com deficiência mental. Inicialmente, relata-se o caso demonstrando as condições em que foi autorizada a laqueadura de Maria. Posteriormente, contextualiza-se a situação vivenciada por Maria na doutrina de direitos humanos em que se percebe a violação da liberdade e intimidade da deficiente, bem como a inobservância dos preceitos bioéticos de consideração dos interesses da paciente diante de procedimentos médicos. Ao final, a investigação promove análise da guinada legislativa propiciada pela Convenção de Nova York e do correspondente Estatuto da Pessoa com Deficiência, no Brasil, ao considerar os deficientes como pessoas capazes, proibindo a correspondente esterilização compulsória. A investigação adota como método de abordagem o hipotético/dedutivo e de procedimento, o histórico/analítico.

PALAVRAS-CHAVES: Esterilização compulsória. Deficiência mental. Direitos humanos.

\section{Maria - interdicted and sterilized: legal reflections about mental disorder}

\begin{abstract}
The study investigates the interests involved in the granting of interdiction and compulsory sterilization claims, through tubal ligation, in the case Maria, a person with mental disorder. Initially, the case is narrated showing the conditions in which was authorizes Maria's ligation. After that, its contextualized the situation lived by Maria in the doctrine of human rights in which is perceived the violation of freedom and intimacy of the disabled person, as well as the lack of observation of the bioethical standards of the consideration of interests of the patient facing medical procedures. Finally, the investigation promotes the analysis of the legal turning point given by the New York convention and the correspondent Statute of the Person with Disability in Brazil through the consideration of disabled persons as capable persons, prohibiting the correspondent compulsory sterilization. The investigation adopted as an approach method the hypothetical/deductive and as procedure, the historic/analytical.
\end{abstract}

KEYWORDS: Compulsory sterilization. Mental disability. Human rights. 


\section{INTRODUÇÃO}

A pesquisa se debruça sobre julgamento que deferiu a interdição e laqueadura compulsória de uma cidadã brasileira, neste estudo denominada Maria. O trabalho encontra pertinência diante dos argumentos que justificam o procedimento de esterilização considerando o contexto legislativo da época e as recentes alterações promovidas pela internalização de compromissos internacionais.

Para tanto, questiona quais os interesses observados no deferimento do pedido de esterilização de Maria, pessoa com deficiência mental. Com isso, aborda inicialmente, a análise do processo envolvendo o caso de interdição e esterilização de Maria, feita por meio de laqueadura tubária ou ligadura de trompas.

Posteriormente, investiga o contexto bioético e de direitos humanos para a contextualização do julgamento e, por derradeiro, o trabalho se dedica à compreensão dos reflexos da Convenção de Nova York nas questões atinentes à esterilização de pessoa com deficiência mental no Brasil, observando a legislação atual do Estatuto da Pessoa com Deficiência, Lei n ${ }^{\circ} 13.146$, de 6 de julho de 2015 .

\section{MARIA, UMA MULHER MENTALMENTE DEFICIENTE E INTERDI- TADA (ACÓRDÃO No 70061015814/TJRS)}

M.F.S.N., neste estudo designada Maria, maior e em idade reprodutiva, teve uma filha aqui nominada Laura e, quanto a esta, não dispensa qualquer cuidado. Oportunamente relatou viver um relacionamento amoroso sem ao menos precisar quem é o suposto namorado, tendo também relatado que se relaciona com diversos namorados.

Neste contexto, Maria apresenta comportamento agressivo frequente, tendo sido diagnosticada com transtorno depressivo bipolar sem controle, pois ainda que sua mãe esteja comprometida com a administração dos medicamentos pertinentes nos horários devidos, ressalta-se a dificuldade de êxito em razão do comportamento agressivo decorrente do transtorno, como também, do acesso precário e interrompido ao medicamento fornecido pelo Sistema Único de Saúde. Maria recebe benefício previdenciário pois no devido processo obteve provimento por ser considerada inapta para o exercício de qualquer atividade laboral em razão de sua situação psicológica.

Em razão desses fatos, S.S.N, nesta pesquisa denominada Sônia, mãe de Maria, em 30/01/2012 ingressou com processo judicial de interdição desta e intervenção cirúrgica de laqueadura tubária, bem como de guarda da filha menor para a tia de Maria, J.S.N., denominada Joana, que possui relação de afinidade com a menina.

A Defensoria Pública foi nomeada curadora especial de Maria no processo. A primeira defesa realizada deu-se por negativa geral, ou seja, nem mesmo restou analisada a questão de fundo imbricada e relacionada aos direitos humanos ou de cidadania, bem como a questão principiológica concernente.

O conjunto probatório foi composto de interrogatório em juízo (fls. 49-50), do laudo médico pericial (fls. 70-75) e do estudo social realizado (fls. 93-94). Por sua vez, o Ministério Público manifestou-se pelo deferimento da ação em sua totalidade, dada a situação concreta de Maria.

A sentença foi procedente em sua totalidade, conforme se vê a seguir: 


\begin{abstract}
Sendo assim, merece prosperar a pretensão apresentada na inicial, uma vez que devidamente comprovado ser a demandada totalmente incapaz de exercer, por si só, os atos da vida civil, aliado ao fato de que a curadora provisória é mãe da requerida enquadrando-se nas hipóteses previstas no art. 1768, inciso II, do CC -, assim como é pessoa adequada para ser curadora da requerida, consoante se extrai do estudo social realizado. (RIO GRANDE DO SUL, TJRS, 2014, fl. 105).
\end{abstract}

Diante disso, a Defensoria Pública recorreu alegando a violação dos direitos humanos de Maria, bem como dos princípios constitucionais como a dignidade da pessoa humana, arguindo ainda sobre o caráter extremo do procedimento pois, antes da laqueadura outros métodos de controle reprodutivo existem como forma de prevenção ou mesmo métodos contraceptivos menos invasivos e que poderiam propiciar a mesma finalidade.

O Ministério Público, ciente das arguições e, no sentido de proteger os direitos humanos da incapaz, afirmou que no caso concreto em debate o melhor a se fazer é desprover o apelo, mantendo a decisão de primeira instância na sua integralidade.

A Relatora Desembargadora manifestou-se no sentido de reconhecer a divergência doutrinária acerca da discussão sobre a violação de direitos da interdita, no entanto, analisando o caso concreto, entendeu que a medida requerida se constitui na melhor forma de proteção da futura criança e da própria interdita:

\begin{abstract}
Como não considerar a alternativa de proteger a incapaz, evitando gestações indesejadas e, anunciadamente, conturbadas, considerando sua vida sexual promíscua e desregrada? Como consentir que uma jovem impossibilitada permanentemente de cuidar de si mesma gere filhos que, certamente, ficarão abandonados à própria sorte, em atitude que põe em risco a sua própria saúde, pois certamente não haverá adesão ao pré-natal? [...] "na compreensão de que a vida é mais rica do que a lei, e muito mais dinâmica do que o processo de edição das normas". (RIO GRANDE DO SUL, TJRS, 2014, grifo nosso).
\end{abstract}

A decisão foi seguida pelos demais Desembargadores que, de forma unânime, negaram provimento ao recurso autorizando a realização do procedimento, bem como a interdição da incapaz e o deferimento da guarda da menor à tia. A comprovação da realização do procedimento foi juntada em 14/08/2015, sendo que nada mais foi arguido ou requerido, tendo, posteriormente, o processo sido baixado. De modo breve, este é o relato do caso que deferiu a laqueadura na incapaz tornando-a estéril.

A partir do relato e colhendo o ensejo de que "a vida é mais rica do que a lei”, conforme referido pela Relatora Desembargadora, segue-se à análise jurídica do caso na ótica de direitos humanos e de reflexões bioéticas.

\title{
2. DIREITOS HUMANOS E BIOÉTICA: REFLEXÕES JURÍDICAS ACERCA DO TRANSTORNO MENTAL: CASO DE MARIA - INTERDI- TADA E ESTERILIZADA
}

O modo como o Estado vislumbra a deficiência repercute diretamente sobre as políticas públicas em saúde. Na Grécia antiga a "desrazão" foi considerada um privilégio por pensadores como Sócrates e Platão que destacaram a loucura como questão divina e mística. Para eles, homens privilegiados poderiam diretamente acessar verdades divinas. (GALENDE; KRAUT, 2006).

Gradativamente, a loucura se distancia do místico e a partir do Renascimento passa a ser vislumbrada como representação do mal. Nesse sentido, constata-se a obra de Erasmo de Roterdã 
Maria - interditada e esterilizada: reflexões jurídicas acerca do transtorno mental

- Elogio da Loucura, que representou crítica severa à loucura. Durante a Idade Média, os loucos foram retirados do convívio em sociedade experimentando a exclusão. (FOUCAULT, 2008).

A partir disso, a loucura se torna objeto do saber médico e recebe a nomenclatura de doença mental. Surgem os hospitais como espaços terapêuticos, de implementação de medidas disciplinares e de vigilância. Nesse aspecto, houve a implementação de vigilância e registro constante para a efetividade ao tratamento do doente mental e a nova ordem estabelecida (FOUCAULT, 1979).

Philippe Pinel tornou-se o expoente médico no século XVIII, responsável pela teoria da liberdade de movimentos questionando a utilização das correntes e inserindo tratamentos morais. Segundo Pinel, a possibilidade de movimentos por si só, promovia melhoras aos doentes mentais, o que deu início ao processo de cientifização dos tratamentos. Deste modo, a desconstrução do conceito de doença mental aconteceu no período pós-guerra a partir do questionamento sobre o modelo hospitalocêntrico sinalizando reformulação no sentido da desinstitucionalização. (FOUCAULT, 2002).

Atualmente, a nomenclatura médica utilizada é a de transtorno mental para promover abordagem diagnóstica descritiva, isto é, reconhecível pelos sintomas ou comportamentos. A OMS apresenta toda a classificação médica acerca dos transtornos mentais, oriunda não de uma causa determinada, mas de fatores biológicos, psicológicos e, sobretudo, socioculturais (OMS, 1993).

Assim, a entidade define como transtornos mentais os estados de depressão caracterizados por sentimentos persistentes de tristeza, desânimo, fadiga; os estados de mania, apontados pela irritabilidade, ideias de grandiosidade, atividade aumentada, pensamento e fala acelerados e sono diminuído. Ainda, a OMS refere como transtorno mental a ansiedade exagerada, medos irracionais; outro transtorno apontado é a esquizofrenia, caracterizada por alucinações auditiva, visual, gustativa ou olfativa. (1993).

Em tais rumos contextualiza-se o caso de Maria, especialmente no que toca à delicada questão referente às funções reprodutivas das pessoas com deficiência mental tendo em vista o aparente conflito de interesses em tela.

Maria, a despeito de ser considerada uma pessoa com deficiência, é uma cidadã brasileira e, por isso, dotada de todos os direitos atinentes aos demais cidadãos. Nesse mote, cabe destacar a complexidade de direitos constantes na carta constitucional brasileira. Destaca-se a consideração dos direitos humanos e liberdades consagradas, pois a Constituição Federal brasileira possui todas as gerações (ou dimensões) dos direitos humanos incluídas em seu bojo. Desde os direitos de liberdade, como direito à vida, liberdade de expressão e patrimônio; direitos de igualdade, sociais, culturais e econômicos, como direito ao trabalho, previdência, direito à educação e saúde; e os de terceira geração, chamados de solidariedade ou fraternidade, como direito à paz e ao desenvolvimento.

Sarlet observa que os direitos humanos incluídos nos ordenamentos jurídicos pátrios passam a ser denominados de direitos fundamentais ou direitos humanos fundamentais, uma vez que representam aqueles direitos que foram considerados fundamentais pelo determinado Estado e que merecem ter guarida constitucional. (2007)

Nesse mesmo sentido, é importante mencionar que os direitos de cidadania, na atualidade, representam o conjunto dos direitos humanos, destacando que sem direitos humanos protegidos, não há como a cidadania prosperar e sem a proteção dos direitos do cidadão, os direitos humanos não existem na esfera concreta. 
Conforme Bobbio afirma, "o problema fundamental em relação aos direitos do homem, hoje, não é tanto o de justificá-los, mas o de protegê-los. Trata-se de um problema não filosófico, mas político" (1992, p. 24, grifo nosso). Assim, a proteção desses direitos mostra-se de grande importância e as lutas históricas sempre se deram no sentido de buscar a proteção de mais direitos.

Nesse sentido, tratando da cidadania como sinônimo do conjunto dos direitos humanos, Bertaso observa que:

\begin{abstract}
Em sua dinâmica, e apesar da dicotomia, ainda afirmada entre os direitos humanos e direitos do cidadão, a concepção moderna de cidadania civil, política, social e solidária, vai tornando-se sinônimo do conjunto dos direitos humanos. Transita-se da ideia do indivíduo, singularmente concebido, primeiro sujeito de direitos, para a ideia de entes coletivos que transcendem o indivíduo, como novos personagens e novos sujeitos de direitos, voltados a exercer e realizar a cidadania de forma mais ampla. (2002, p. 423)
\end{abstract}

Ainda, deve-se destacar que cidadania deve representar ideais de alteridade, respeito, tolerância, empatia, inclusão. Nesse sentido, compreende-se a cidadania como reconhecimento social, inclusão, dignidade para todos sendo condição base para uma sociedade na qual os direitos funcionam como referencial ético-jurídico da sociedade de cidadãos(ãs). (BERTASO; BERTASO, 2015, p. 50-1).

Cidadania também representa participação, ter voz e vez. É participar da tomada de decisões, ter seus anseios ouvidos e, mais do que isso, acolhidos ou, ao menos, respeitados. A cidadania constrói-se com a participação popular. Assim, é possível perceber que onde não há respeito aos direitos humanos, onde não são dadas condições para a concretização desses direitos, não existe como a cidadania prosperar e se mostrar eficiente. Não existe como o cidadão sentirse pleno em seus direitos e deveres onde não há garantias de que ele possa efetivamente exercer seus direitos e viver com dignidade, onde a pessoa humana seja na verdade subcidadão. (SOUZA, 2018).

Percebe-se que Maria, no contexto trazido aos autos analisados, foi considerada como uma subcidadã. Ou seja, ela não teve voz, nem vez. Sua opinião foi totalmente desconsiderada na tomada de decisões, nem ao menos foi questionada sobre a possibilidade de utilização de métodos contraceptivos. Na caminhada histórica pelo reconhecimento de direitos, percebe-se que algumas pessoas sempre tiveram mais acesso aos seus direitos que outras. Nesse caso, mesmo que o direito à igualdade esteja presente desde as primeiras declarações de direitos (art. $1^{\circ}$, da Declaração dos Direitos do Homem e do Cidadão, 1789), alguns foram relegados ao segundo plano, e esse é o caso relativo à deficiência mental, tradicionalmente denominado como "loucura".

A matéria é delicada em razão dos registros históricos de esterilização compulsória como por exemplo, os verificados durante a $2^{\mathrm{a}}$ Guerra Mundial a partir da ascensão da ideologia nazista que propagava a purificação da espécie, o que seria possível por procedimentos de esterilização compulsória nos campos de concentração. Nesse sentido, Hitler refere em sua obra "Mein Kampf":

A exigência de que os deficientes sejam impedidos de propagar uma prole de deficientes como eles é uma exigência da mais clara razão e, se sistematicamente executada, representa o mais humano dos atos da humanidade. Poupará milhões de desafortunados de sofrimento desmerecido e consequentemente levará a uma melhoria da saúde como um todo (1983, p. 274).

A ideologia nazista conseguiu adesão com a promessa de construção de um mundo de beleza e perfeição alcançado mediante o melhoramento da espécie humana com a total exclusão 
Maria - interditada e esterilizada: reflexões jurídicas acerca do transtorno mental

de judeus, ciganos, homossexuais e pessoas com qualquer deficiência. Os propósitos das medidas de esterilização compulsória foram propiciados pela política eugenista nazista. (ARQUITETURA DA DESTRUIÇÃO, 1989).

Tais atrocidades foram objeto de julgamento em Nuremberg e como resultado surgiu o Código de Nuremberg que estabeleceu os preceitos norteadores da pesquisa científica com seres humanos e das práticas em saúde. Muito embora suas diretrizes tenham adquirido amparo legal apenas nos anos de 1970 com a Declaração de Helsinque, o documento consolidou a autonomia do participante da pesquisa, caracterizada pelo devido esclarecimento dos objetivos da pesquisa, bem como os riscos e benefícios decorrentes; ainda, a garantia de beneficência, isto é, que o participante da pesquisa possa observar benefícios decorrentes do experimento, e também, a justa distribuição dos benefícios com a observância do princípio da justiça.

A temática pode ser encontrada na Declaração Universal sobre Bioética e Direitos Humanos da UNESCO de 2005 - DUBDH. Conforme destaca o artigo $7^{\circ}$ "a autorização para [...] prática médica deve ser obtida no melhor interesse do indivíduo envolvido e de acordo com a legislação nacional [...]". O documento ainda destaca que "o indivíduo afetado deve ser envolvido, na medida do possível, tanto no processo de decisão do consentimento assim como no de sua retirada". (UNESCO, 2005).

Nesta senda, oportuna a consideração acerca do princípio da beneficência, tido como o dever de promover o bem do paciente por meio do procedimento (BEAUCHAMP; CHILDRESS, 2002) e, ainda, da observância do termo de consentimento livre e esclarecido que deve ser assinado pelo paciente legitimando sua voluntariedade na esterilização cirúrgica. $\mathrm{O}$ referido apresenta-se como reflexo do princípio bioético da autonomia, que preceitua o conhecimento sobre os riscos e benefícios inerentes ao procedimento. (BEAUCHAMP; CHILDRESS, 2013).

Deste modo, busca-se proteger o sujeito da realização de uma intervenção sem a sua autorização ou no desconhecimento das consequências do praticado. Para os autores, a prática de um ato deve preencher os requisitos de intencionalidade, entendimento e ausência de coerção. Especificamente com relação às pessoas com deficiência mental que não podem exercer sua autonomia de forma plena e livre, o entendimento e a inexistência de coerção são elementos que variam, dependendo da complexidade da deficiência mental e do contexto familiar verificado.

Esta análise implica considerar que no caso em comento, a laqueadura de trompas surge como medida radical e, ainda, percebe-se que no caso concreto não vislumbrou a melhor conduta para a paciente dada a existência de diversos métodos contraceptivos alternativos como dispositivos intrauterinos e aplicações do medicamento via intramuscular, com um mínimo de reações adversas.

O contexto evidenciado pela perícia destaca quadro de transtorno mental que pode ser controlado mediante o uso de medicamentos adequados e em conformidade com a prescrição médica (fls. 72). Entretanto, a família relata a insuficiência no fornecimento dos medicamentos e, a dificuldade de controlar o transtorno de Maria, bem como sua agressividade.

Deste modo, a esterilização de Maria surge como medida tranquilizadora para a família e para o Estado, entretanto, em nada contribui para a qualidade de vida da paciente que poderia evitar os infortúnios do procedimento se recebesse o devido acompanhamento do Estado de modo transdisciplinar, nos centros de atenção psicossocial. Assim, enquanto poderia ser enfrentada a questão de fundo para a problematização do atendimento em saúde enquanto dever, notase o raciocínio elaborado sobre a saúde enquanto direito.

Em geral, percebe-se argumentos na senda da autoproteção destas pessoas que em razão da própria deficiência poderiam causar riscos à própria saúde. De outra banda, refere-se também 
a proteção atinente ao grupo familiar. Neste contexto, o Estado deve respeitar a autonomia da pessoa com deficiência mental, "salvo nos casos em que o exercício livre do planejamento familiar cause mal a si mesmo ou outrem, ou se existir absoluta incapacidade de compreensão dos atos”. (ALBUQUERQUE, 2013, p. 21).

Não há dúvidas de que a situação vivenciada por Maria e sua família é de alta complexidade, caso em que é percebida significativa colisão de direitos. Expressões como "vida sexual promíscua e desregrada", conforme se observa na manifestação da desembargadora relatora, permitem questionar se esta seria a fundamentação adequada para justificação da autorização de esterilização compulsória.

Nota-se a incongruência da medida e a fundamentação esboçada a partir da bioética principialista que orienta a realização de procedimentos em saúde de acordo à beneficência, ou seja, em conformidade com o melhor interesse e bem-estar do paciente. Por óbvio, o justo acesso aos medicamentos e o controle sobre o transtorno diagnosticado para viabilizar convivência harmônica, não constituíram objeto de análise e tutela por parte dos julgadores.

Deste modo, é pertinente observar a tendência de aplicação irrestrita da medida demonstrando a fragilidade de proteção para os vulneráveis que encontra fundamento jurídico na Lei $\mathrm{n}^{\circ} 9.263$ de 1996 referente ao planejamento familiar. Em seu $10^{\circ}$ dispositivo constam as hipóteses em que a esterilização voluntária é permitida evidenciando que mesmo diante do desejo das pessoas em se submeter ao procedimento, apresenta-se legalmente restrita. (BRASIL, 1996). O mesmo entendimento também se encontra no artigo $\mathrm{n}^{\circ} 15$ do regramento civil atual, ressaltando que "ninguém pode ser constrangido a submeter-se, com risco de vida, a tratamento médico ou a intervenção cirúrgica". O referido encontra-se dentre os direitos da personalidade, expressamente enunciados como intransmissíveis e irrenunciáveis e, ainda, objeto de reparação de danos diante de lesão ou ameaça de direito, conforme o artigo $n^{\circ} 12$. (BRASIL, 2002).

Diante de tais constatações, é possível afirmar o repúdio à esterilização compulsória no ordenamento jurídico brasileiro pois, enquanto cirurgia invasiva constitui-se em lesão à integridade física de modo irreversível.

Entretanto, o artigo $10^{\circ}$ da Lei do Planejamento Familiar estabelece em seu $6^{\circ}$ parágrafo a esterilização de pessoas absolutamente incapazes mediante autorização judicial, ou seja, de modo compulsório. Assim, constata-se a legalidade do procedimento ao tempo dos fatos narrados, mantendo-se questionável enquanto medida irreversível e quiçá, dispensável diante da afirmação da perícia de que o transtorno pode ser controlado mediante "tratamento rigoroso" com a administração do medicamento pertinente (fls. 72), e de que a incapacidade da paciente "a princípio é temporária, porque [...] embora se trate de caso grave, ainda não esgotou as possibilidades terapêuticas existentes para a condição" (fls. 74).

Assim, verifica-se a autorização e realização de laqueadura de trompas como medida de resolução ágil de acordo com o pedido da família, entretanto, verifica-se sua inconformidade com os interesses da paciente que não tem acesso às políticas públicas de saúde conforme preconiza a Carta Magna e a Lei da Reforma Psiquiátrica. Nesse paradigma, seria possível o controle do transtorno e igualmente o controle da fertilidade de Maria. Em tais termos, seria verificável o respeito à sua integridade e demais direitos humanos fundamentais. 


\section{ESTERILIZAÇÃO EM SITUAÇÃO DE DEFICIÊNCIA MENTAL NO CONTEXTO DO ESTATUTO DA PESSOA COM DEFICIÊNCIA NO BRA-} SIL

A regulação da vida dos deficientes mentais já existia antes mesmo da codificação nacional, desde a vigência das Ordenações Filipinas de Portugal no Brasil. O Livro I, artigo 66, 3, referia o exercício do poder de polícia "contra o perigo proveniente da divagação dos loucos, dos embriagados, de animais ferozes, ou danados, e daqueles, que, correndo, podem incomodar os habitantes". Conforme Maurício Requião, encontravam-se sujeitos ao poder de polícia o embriagado e o louco que posteriormente integrariam o rol de incapazes na legislação civil. (REQUIÃO, 2016).

Assim, a primeira legislação brasileira relacionada às pessoas com deficiência mental data de 1903 com o Decreto ${ }^{\circ} 1.132$ que inovou ao considerar a guarda dos bens dos alienados, a possibilidade de alta, a proibição de mantê-los em cadeias públicas e a inspeção dos asilos feita por comissão determinada pelo Ministro da Justiça. A legislação ainda garantiu as condições necessárias para o funcionamento do asilo, o pagamento das diárias dos doentes, a composição dos trabalhadores do Hospício Nacional e das colônias de alienados (BRASIL, 1903).

A incapacidade civil determinada pela Lei $\mathrm{n}^{\circ} 3.071$, de 1916, que estabeleceu em seu artigo $5^{\circ}$ a total incapacidade das pessoas com sofrimento mental. (BRASIL, 1916). Apenas com a Constituição Federal de 1988 inicia-se perspectiva de mudança quando apresenta uma gama de direitos humanos em seu bojo. É possível perceber sua vocação para a garantia dos direitos de liberdade já no início da Carta Constitucional, em especial no art. $5^{\circ}$, quando traz a proteção do direito à vida, à liberdade de expressão, proibição da tortura, direito de propriedade, dentre outros. (BRASIL, 1988).

A dignidade da pessoa humana constitui o princípio fundamental representando garantia para que o cidadão brasileiro seja tratado com dignidade, tendo seus direitos humanos fundamentais respeitados. Conforme já mencionado, também é constatada a proteção dos direitos sociais como direito ao trabalho, direito à saúde, direito à educação e previdência. De igual forma, tem-se os denominados direitos humanos de terceira geração, também chamados de solidariedade ou de fraternidade, como direito ao meio ambiente, patrimônio histórico, ao desenvolvimento e à paz.

A Declaração de Pequim de 1995, já identificou a restrição das aspirações femininas na existência diária, seja pela discriminação, injustiça social e econômica que impede a participação equitativa na sociedade. Por isso, o documento destaca como fundamental a proteção da família para que as mulheres possam se desenvolver e acessar os bens que a sociedade oferece. Enfatiza especialmente, as preocupações norteadoras das ações do Estado para a concretização dos direitos da mulher e, aponta o desrespeito aos direitos humanos com o cerceamento de informações completas sobre os serviços disponibilizados pelo Estado, de modo que por outro viés, percebese o atendimento médico impróprio que "redunda em cirurgias evitáveis e medicação imprópria". (ONU, 1995).

Diante de todo o verificado, apresenta-se o sopesamento de direitos garantidos constitucionalmente, no sentido de dar preferência ao planejamento familiar e à preservação da saúde da incapaz que não poderia, sozinha, segundo os laudos juntados aos autos, realizar uma contracepção eficiente e poderia até atentar contra a própria saúde ao ter uma gravidez indesejada.

Com base no laudo médico e na avaliação apresentados pela assistente social, foi determinado que a incapaz nunca seria curada da doença psiquiátrica acometida e, tampouco que a 
mesma pudesse ser controlada uma vez que não tinha acesso ao tratamento contínuo, tornandoo inadequado aos resultados pretendidos. Tendo sido interditada, não houve qualquer interesse sobre as intenções da incapaz em ter filhos no futuro.

Na realidade, a incapaz foi muito pouco questionada ou ouvida sobre suas pretensões, de modo que as informações do processo constituíram o suporte fático determinante para que o magistrado prolatasse a sentença que deferiu a interdição de Maria e a correspondente laqueadura de trompas, sendo unanimemente mantida em segunda instância.

Observa-se nos laudos médicos que o transtorno que acomete a paciente pode ser controlado por meio do acesso ao medicamento de uso contínuo e da administração adequada. Nota-se a violação aos direitos de Maria quando lhe retiram a possibilidade de opção por outros meios contraceptivos temporários e de procedimento reversível.

Ainda, complementa-se acerca da violação de direitos no que toca à violação do próprio corpo mediante realização de procedimento irreversível e que pode trazer, também, consequências para a saúde da incapaz, como aumento nos sangramentos vaginais e aumento na depressão, doença essa já existente, podendo ser agravada. (DIAS, s.a, p. 104).

Recentemente, o Conselho Nacional dos Direitos da Criança e do Adolescente - CONANDA -, manifestou nota de repúdio à esterilização compulsória em razão da grave violação de direitos ocasionada pelo procedimento. Tal nota deu-se por meio do Ofício-Circular $\mathrm{n}^{\circ}$ 22/2018/SEI/CONANDA/SNDCA/MDH. (CONANDA, 2018).

A razão do repúdio se refere ao Caso Janaína ${ }^{1}$, que não pediu para se submeter ao procedimento de esterilização e, mesmo assim, restou determinada sua realização de forma compulsória em razão da mulher estar gerando o oitavo filho, ser pobre e dependente química. Segundo o CONANDA, a nota de repúdio reconhece "essa prática como uma grave violação dos direitos humanos, baseada em concepções de controle de natalidade como forma de repressão à pobreza (CONANDA, 2018).

Ademais, diante do julgado procedente em primeira instância, na cidade de Mococa, São Paulo houve interposição de recurso que reverteu a situação, mas não pode produzir efeitos práticos em razão de que o procedimento já havia sido realizado. No referido acórdão, entendeu-se que, mesmo com a incapacidade da mulher, o procedimento não poderia ser realizado pois "inexiste notícia de interdição judicial, com submissão à curatela legal, tudo a indicar que a compulsoriedade da laqueadura representaria, aqui, grave afronta ao princípio da dignidade da pessoa humana" (TJSP - Apelação no 1001521-57.2017.8.26.0360).

Nesse sentido, o procedimento caracteriza-se em medida extrema, podendo ser realizado quando a mulher, voluntariamente aceita submeter-se, dada a irreversibilidade verificada e a violação ao corpo da mulher, alterando sobremaneira suas características biológicas básicas. Constata-se então, a coerção da medida como um ato estatal arbitrário, contrário aos direitos humanos e aos direitos da mulher como cidadã brasileira que não tem liberdade de escolha, afrontando sobremaneira sua dignidade.

Contemporaneamente percebe-se a guinada em torno do entendimento de deficiência mental a partir do Estatuto da Pessoa com Deficiência - Lei n ${ }^{\circ} 13.146 / 2015$, que estabeleceu a capacidade plena da pessoa deficiente, inclusive para conservar sua fertilidade vedando a esterilização compulsória conforme artigo $6^{\circ}$, inciso IV. (BRASIL, 2015).

1 MENDES; VIVIANI, 2019. 
Maria - interditada e esterilizada: reflexões jurídicas acerca do transtorno mental

O entendimento é promovido em face da Convenção de Nova York sobre os Direitos das Pessoas com Deficiência da ONU, ratificada pelo Brasil em 2008, obtendo a equivalência de Emenda Constitucional, por meio do Decreto Legislativo 186, de 09 de julho, e promulgada no Brasil por meio do Decreto ${ }^{\circ}$ 6.949, de 25 de agosto de 2009.

Assim, o Brasil firmou compromisso no sentido de providenciar medidas para eliminar a discriminação contra pessoas com deficiência em todos os aspectos da vida social. Observa-se no teor do artigo 23 da Convenção o reconhecimento do "direito das pessoas com deficiência, em idade de contrair matrimônio, de casar-se e estabelecer família, com base no livre e pleno consentimento dos pretendentes", decidindo ainda sobre "o número de filhos e o espaçamento entre esses filhos e de ter acesso a informações adequadas à idade e à educação em matéria de reprodução e de planejamento familiar, bem como os meios necessários para exercer esses direitos”. (BRASIL, 2015).

Diante deste novo contexto internalizado pelo Brasil, as pessoas deficientes não são sempre consideradas incapazes ou mesmo relativamente capazes, conforme pode ser observado na alteração do artigo $3^{\circ}$ do Código Civil (BRASIL, 2002), dependendo do caso concreto (apenas quando necessário, a pessoa com deficiência será submetida à curatela $\left(\operatorname{art} .84, \S 1^{\circ}\right.$, Lei $n^{\circ}$ 13.146/2015). Desse modo, diante de tal mudança legislativa devem estar integradas e, em sua autonomia, exercendo os direitos reprodutivos, bem como o planejamento familiar.

Nesse mote, nota-se incentivo e estímulo à autonomia da pessoa com deficiência mental para integrá-la, inclusive no mercado de trabalho, com o pressuposto de que afastando as barreiras sociais todas as pessoas com deficiência conseguirão ser incorporadas ou incluídas socialmente. Entretanto, percebe-se circunstâncias em que tais esforços demonstram-se inúteis, como nos casos severos de deficiência mental. Em tais rumos, Diniz ressalta a prevalência do paradigma da solidariedade e interdependência em razão da extrema vulnerabilidade. (2003, p. 4). Com esse viés, a proteção à pessoa deficiente tem de considerar a prática do silêncio por parte de pessoas e, até mesmo instituições que conhecem situações de abuso e nada referem, o que contribui para a impunidade.

Entretanto, a partir dos reflexos internos da Convenção de Nova York, os julgados mais recentes estão impedindo a realização da laqueadura tubária, como pode ser vislumbrado:

\begin{abstract}
APELAÇÃO CÍVEL. FAMÍLIA. CURATELA. PEDIDO DE EXPEDIÇÃO DE ALVARÁ JUDICIAL PARA REALIZAÇÃO DE LAQUEADURA TUBÁRIA EM PESSOA SUBMETIDA À CURATELA. INDEFERIMENTO DO PEDIDO. ALTERAÇÕES NO CÓDIGO CIVIL PROMOVIDAS PELO ESTATUTO DA PESSOA COM DEFICIÊNCIA.

SUBMISSÃO À CURATELA QUE NÃO IMPLICA A ABSOLUTA INCAPACIDADE. EXPRESSA VEDAÇÃ̃O DE REALIZAÇÃO DE ESTERILIZAÇÃO COMPULSÓRIA (Apelação Cível No 70072208580, Oitava Câmara Cível, Tribunal de Justiça do RS, Relator: Luiz Felipe Brasil Santos, Julgado em 09/03/2017)
\end{abstract}

Observa-se a congruência do julgado com os preceitos do Estatuto da Pessoa com Deficiência, ainda que diante do mesmo contexto, no Estado de São Paulo, o Tribunal tenha reformado sentença que julgou improcedente o pedido de realização de laqueadura tubária, veja-se:

AÇÃO ORDINÁRIA - Saúde pública - Pretensão de realização de cirurgia de la-
queadura tubária em pessoa absolutamente incapaz - Possibilidade - Quadro de sa-
úde irreversível - Ausência total de capacidade de se autodeterminar, inclusive sexu-
almente - Dever de assistência à saúde e de atenção ao princípio da dignidade da
pessoa humana - Laudo médico recomendando a adoção da medida - Precedentes -
Ação julgada improcedente em primeira instância - Sentença reformada - Recurso
provido. (TJSP; Apelação Cível 0000134-13.2013.8.26.0312; Relator (a): Leme de 


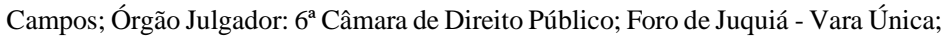
Data do Julgamento: 05/03/2018; Data de Registro: 12/03/2018)

O disposto na ementa considerada aponta para a consideração do procedimento de modo compulsório a partir do dever de assistência em saúde. O mesmo é observado na situação de Maria, conforme relato supra, de modo que a medida aparece como solução para as possíveis consequências das circunstâncias vividas por Maria, enquanto espera-se que medidas globais sejam providenciadas, como por exemplo a assistência em saúde mental por meio dos Centros de Atenção Psicossocial - CAPs, como clínicas para o incentivo à autonomia, responsabilização e protagonismo na trajetória de tratamento, até mesmo para os casos severos e persistentes.

Nesse aspecto, é considerado o disposto pela Lei da Reforma Psiquiátrica $-\mathrm{n}^{\circ}$ 10.216/2001, que estabelece serviços de saúde ofertados nos munícipios de modo aberto e comunitário para o atendimento diário de acompanhamento clínico e a reinserção social por meio do acesso ao trabalho, lazer, exercício dos direitos civis e fortalecimento dos laços familiares e comunitários. (BRASIL, 2001).

No caso em análise, nota-se a possibilidade de controle sobre os transtornos que acometiam Maria por meio da atuação da assistência referida, inclusive no sentido de estimular o controle de fertilidade por métodos injetáveis, por exemplo. A esterilização não é a única solução contraceptiva para as mulheres dotadas de incapacidade mental, podendo haver recurso, por exemplo, a métodos de contracepção hormonal confiáveis [...]. Há ainda, métodos injetáveis, que asseguram um tempo maior de proteção contra o risco de engravidar. (MARTINS-COSTA, 2009, p. 338).

Nessa senda, a referência acima está de pleno acordo com as premissas do Estatuto ao assegurar que a deficiência em nada obsta o exercício do planejamento familiar e dos direitos reprodutivos, não havendo, portanto, empecilhos decorrentes da deficiência para a esterilização voluntária. Entretanto, a observância literal da norma pode significar no plano prático a autorização de esterilização em pessoa que nem mesmo compreenda os objetivos práticos do procedimento de laqueadura.

Em tais termos, as circunstâncias em que Maria foi submetida à esterilização compulsória demonstram a consideração de interesses outros, que não os da própria deficiente, quando perceptível o agravamento do transtorno diante da dificuldade na obtenção de atendimento em saúde mental e medicamentos devidos.

\section{CONCLUSÃO}

A gradativa trajetória da humanidade na consagração de direitos incorpora as pessoas com deficiência mental apenas no século XXI. Denominadas loucas, desarrazoadas, tomadas pelo mal ou pelo divino, a deficiência mental encontra tutela de dignidade contemporaneamente com as alterações legislativas promovidas no Brasil pelo Estatuto da Pessoa com Deficiência.

Nesse diapasão, a pesquisa não tem a pretensão de encontrar razões para o total questionamento da medida de esterilização por laqueadura tubária pois diversas são as peculiaridades dos casos que cabe ao Poder Judiciário analisar. Especificamente, com relação ao caso relatado verifica-se a legalidade do procedimento de laqueadura, constatada a incapacidade da deficiente com o deferimento do pedido de interdição. O contexto do julgamento de Maria é complexo teve sua deficiência agravada em virtude da ineficácia do sistema de saúde, especialmente no modelo de atendimento psicossocial em desconformidade com os compromissos internacionais assumidos pelo Brasil ao instituir a Lei de Reforma Psiquiátrica. 
Na prática, a letra da lei não apresenta efeitos no que toca ao controle do transtorno mental por medicamentos de uso ininterrupto. A situação também impede a boa convivência familiar, de modo que Sônia não conseguia acompanhar o tratamento de sua filha Maria e o procedimento de laqueadura, ainda que radical, apresentou-se como solução para todo o contexto percebido, mesmo sem contribuir para o tratamento que a deficiente merece e espera.

Os argumentos referidos na decisão apresentam visão superficial da questão ao deferir o procedimento em razão da vida sexual desregrada de Maria que em juízo confirmou ter muitos namorados. Ainda, observa-se o fato da deficiente ser agressiva mesmo diante da manifestação do perito de que o controle sobre o transtorno dependeria do uso ininterrupto de medicamentos adequados. Nesse sentido, a própria deficiente destacou o desconforto aumentado quando não conseguia obter os medicamentos junto à rede pública de saúde.

Outro aspecto referido, tanto na primeira quanto na segunda instância, é o de proteger a incapaz da gravidez indesejada e de doenças sexualmente transmissíveis. Quanto ao último aspecto, além da dúvida, conclui-se pela incredulidade do uso de tal argumento. Claramente, o Poder Judiciário corrobora a lei do menor esforço deferindo pedido de esterilização em razão de deficiência mental sem questionar as razões da gravidade em que a deficiente se encontra, sem refletir ou considerar o atendimento de saúde ofertado à Maria e, tampouco, observar a pertinência de métodos alternativos de contracepção.

A esterilização compulsória observada demonstra total desconsideração dos direitos de Maria que apresenta lucidez ao referir que se torna agressiva diante do não acesso aos medicamentos. Nesse tom, considera-se a arbitrariedade do julgamento e a vulnerabilidade de Maria que contemporaneamente permanece acorrentada, sem o devido tratamento.

Por derradeiro, pondera-se a real evolução da tutela dos direitos das pessoas com deficiência mental que contrariamente à proposta de tratamento oitocentista de Philippe Pinel, ainda se encontram agrilhoados em face da retórica legislativa.

\section{REFERÊNCIAS}

ARQUITETURA da Destruição. Direção e Produção: Peter Cohen. Narração: Rolf Arsenius (Sueco), Bruno Ganz (Alemão), Sam Gray (Inglês). Roteiro: Peter Cohen. 1989. 119 min. Disponível em: https://www.youtube.com/watch?v=gDqGT4xepjQ Acesso em 20 fev. 2019.

ALBUQUERQUE, A. A. Esterilização compulsória de pessoa com deficiência intelectual: análise sob a ótica do princípio da dignidade da pessoa humana e do respeito à autonomia do paciente. Bioethikos, São Paulo, v. 7, n. 1, p. 1826, 2013.

BEAUCHAMP, T.L. \& CHILDRESS, J.F. Princípios de Ética Biomédica. 4.ed. São Paulo: Loyola, 2002.

BEAUCHAMP, T. L.; CHILDRESS, J. F. Respect for autonomy. In: BEAUCHAMP T. L., CHILDRESS, J. F. Principles of Biomedical Ethics. 7. ed. New York: Oxford University, 2013.

BERTASO, João Martins. A cidadania moderna: a leitura de uma transformação. In: DAL RI JÚNIOR, Arno; OLIVEIRA, Odete Maria de (orgs.) et al. Cidadania e Nacionalidade: efeitos e perspectivas: nacionais - regionais - globais. Ijuí: Unijuí, 2002.

BERTASO, João Martins; BERTASO, Candice Nunes. Dialética de Sinergia entre Cidadania e Direitos Humanos. In: BERTASO, João Martins; SANTOS, André Leonardo Copetti; ROCHA, 
Leonel Severo (org.). Cidadania e Direitos Culturais: a tutela judicial das minorias e hipossuficientes no Brasil. Santo Ângelo: FURI, 2015, p. 45-70.

BOBBIO, Norberto. A Era dos Direitos. 13ª tiragem. Rio de Janeiro: Campus, 1992.

BRASIL. Decreto $\mathbf{n}^{\circ} \mathbf{1 . 1 3 2}$ de 1903. Reorganiza a assistência aos alienados. Disponível em https://www2.camara.leg.br/legin/fed/decret/1900-1909/decreto1132-22-dezembro-1903-

585004-publicacaooriginal-107902-pl.html Acesso em 30 maio 2019.

BRASIL. Lei no 3.071 de 1916. Código Civil dos Estados Unidos do Brasil. Disponível em: http://www.planalto.gov.br/ccivil_03/leis/13071.htm Acesso em: 30 maio 2019

BRASIL. Lei $\mathbf{n}^{\circ} 9.263$ de 1996. Regula o $\S 7^{\circ}$ do art. 226 da Constituição Federal, que trata do planejamento familiar, estabelece penalidades e dá outras providências. Disponível em: http://www.planalto.gov.br/ccivil_03/LEIS/L9263.htm. Acesso em: 30 maio 2019

BRASIL. Decreto no 6.949 de 2009. Promulga a Convenção Internacional sobre os Direitos das Pessoas com Deficiência e seu Protocolo Facultativo, assinados em Nova York, em 30 de março de 2007. Disponível em: http://www.planalto.gov.br/ccivil_03/_ato2007-2010/2009/decreto/d6949.htm. Acesso em: 26 maio 2019.

BRASIL. Lei $\mathbf{n}^{0} \mathbf{1 0 . 2 1 6}$ de 2001. Dispõe sobre a proteção e os direitos das pessoas portadoras de transtornos mentais e redireciona o modelo assistencial em saúde mental. Disponível em: http://www.planalto.gov.br/ccivil_03/leis/leis_2001/110216.htm. Acesso em: 26 maio 2019.

BRASIL. Lei no 13.146 de 2015. Institui a Lei Brasileira de Inclusão da Pessoa com Deficiência (Estatuto da Pessoa com Deficiência). Disponível em: http://www.planalto.gov.br/ccivil_03/_ato2015-2018/2015/lei/113146.htm. Acesso em: 26 maio 2019.

CONANDA. Conselho Nacional dos Direitos da Criança e do Adolescente. Disponível em: http://www.crianca.mppr.mp.br/2018/07/20636,37/NOTAPUBLICA-CONANDA-repudia-esterilizacao-compulsoria-e-destituicao-indevidade-poder-familiar.html. Acesso em: 26 set. 2018.

DIAS, Daniel Spadoto. Repercussões Clínicas e Psíquicas da Laqueadura Tubária Videolaparoscópica. Disponível em: http://www.iamassis.com.br/artigos/tese\%20mestrado\%20Dr.Daniel\%20Spadotto.pdf Acesso em: 26 set. 2018.

DINIZ, Débora. Modelo Social da Deficiência: a crítica feminista. Série Anis, v. 28, Brasília, jul. 2003.

FOUCAULT, Michel. Eu, Pierre Rivière, que degolei minha mãe, minha irmã e meu irmão: um caso de parricídio do século XIX. Traduzido por Denize Lezan de Almeida, 1979.

FOUCAULT, Michel. História da Loucura na Idade Clássica. Traduzido por José Teixeira Coelho Netto. 8. ed. São Paulo: Perspectiva, 2008.

FOUCAULT, Michel. Os Anormais. São Paulo: Martins Fontes, 2002.

GALENDE, Emiliano; KRAUT, Alfredo Jorge. EI Sufrimiento Mental: el poder, la ley y los derechos. Buenos Aires: Lugar Editorial, 2006.

HITLER, Adolf. Minha Luta. São Paulo: Moraes, 1983.

MARTINS-COSTA, Judith. Capacidade para consentir e esterilização de mulheres tornadas incapazes pelo uso de drogas: notas para uma aproximação entre a técnica jurídica e a reflexão bioética. In: MARTINS-COSTA, Judith; MÖLLER, Letícia Ludwig (org.). Bioética e Responsabilidade. Rio de Janeiro: Forense, 2009. 
MENDES, Guilherme; VIVIANI, Luís. Como um juiz e um promotor determinaram a esterilização de uma moradora de rua? Disponível em: https://jotainfo.jusbrasil.com.br/noticias/588430829/como-um-juiz-e-um-promotor-determinaram-a-esterilizacao-de-uma-moradora-de-rua Acesso em: 9 out. 2019.

OMS. Classificação de Transtornos Mentais e de Comportamento da CID10: descrições clínicas e diretrizes diagnósticas. Porto Alegre: Artes Médicas, 1993.

ONU. Declaração e plataforma de Ação da IV Conferência Mundial sobre a Mulher. Pequim, 1995. Disponível em http://www.unfpa.org.br/Arquivos/declaracao_beijing.pdf Acesso em 19 out. 2018.

REQUIÃO, Maurício. As mudanças na capacidade e a inclusão da tomada de decisão apoiada a partir do estatuto da pessoa com deficiência. Revista de Direito Civil Contemporâneo. vol. 6, p. 37-54, jan./mar. 2016.

RIO GRANDE DO SUL. Tribunal de Justiça. Apelação Cível No 70061015814, Sétima Câmara Cível, Tribunal de Justiça do RS, Relator: Sandra Brisolara Medeiros, Julgado em 24/09/2014. Disponível em: http://www.tjrs.jus.br/busca/search?q=70061015814\&proxystylesheet=tjrs_index\&client $=$ tjrs_index \&filter $=0 \&$ getfields $=* \& a b a=j u r i s \& e n t s p=a \_$politicasite $\& w c=200 \& w c \_m c=1 \& o e=U T F-8 \& i e=U T F-$ $8 \&$ ud=1\&sort=date $\% 3 \mathrm{AD} \% 3 \mathrm{AS} \% 3 \mathrm{Ad} 1 \&$ as_qj=\&site=ementario\&as_epq=\&as_ oq=\&as_eq=\&as_q=+\#main_res_juris. Acesso em: 26 maio 2019.

SÃO PAULO. Tribunal de Justiça. Apelação no 1001521-57.2017.8.26.0360. Disponível em: https://www.migalhas.com.br/arquivos/2018/6/art2018061112.pdf. Acesso em: 26 set. 2018.

SARLET, Ingo Wolfgang. A Eficácia dos Direitos Fundamentais. 7. ed. rev. e ampl. Porto Alegre: Livraria do Advogado, 2007.

SOUZA, Jessé. Subcidadania Brasileira: para entender o país além do jeitinho brasileiro. Rio de Janeiro: LeYa, 2018.

UNESCO. Declaração Universal sobre Bioética e Direitos Humanos de 2005. Disponível em: http://bvsms.saude.gov.br/bvs/publicacoes/declaracao_univ_bioetica_dir_hum.pdf Acesso em 30 maio 2019.

Recebido em: 5 jun. 2019.

Aceito em: 20 nov. 2019. 